\title{
Development of model equations for predicting gasoline blending properties
}

\author{
M. K. Oduola ${ }^{1,2}$, A. I. Iyaomolere ${ }^{2}$ \\ ${ }^{1}$ Department of Chemical Engineering, University of Port Harcourt, Port Harcourt, Nigeria \\ ${ }^{2}$ Centre for Gas, Refining and Petrochemicals, Institute of Petroleum Studies, University of Port Harcourt, Port Harcourt, Nigeria
}

Email address:

koyejo.oduola@uniport.edu.ng (M. K. Oduola), adeiyaomo@cgrpng.org (A. I. Iyaomolere)

\section{To cite this article:}

M. K. Oduola, A. I. Iyaomolere. Development of Model Equations for Predicting Gasoline Blending Properties. American Journal of Chemical Engineering. Special Issue: Developments in Petroleum Refining and Petrochemical Sector of the Oil and Gas Industry.

Vol. 3, No. 2-1, 2015, pp. 9-17. doi: 10.11648/j.ajche.s.2015030201.12

\begin{abstract}
Gasoline blending is of pertinent importance in refinery operations owing to the fact that gasoline gives about 60 $70 \%$ of the refinery profit. The blending process is essential to obtain gasoline in the demanded quantities and ensure property specifications are met. Two model equations, multivariable nonlinear and multivariable exponential are proposed in this study which are useful in predicting three significant properties of a motor gasoline: research octane number, reid vapour pressure and specific gravity. Gasoline blend data obtained from four different streams: straight run gasoline, straight run naphtha, reformate and fluidized catalytically cracked gasoline have been subjected to multivariate regression analysis with the aid of a statistical software to ascertain the fitness of the proposed equations in predicting the research octane number, reid vapor pressure and the specific gravity of the resulting premium motor spirit. The results of the regression analysis showed that the nonlinear multivariable models proposed gave a good fit as evidenced by the value of the coefficient of determination $\mathrm{R}^{2}=0.988$ \& 0.994 for the research octane number, $0.853 \& 0.883$ for the reid vapor pressure and 0.988 for specific gravity. In conclusion, the proposed model equations were fit to the data, found to be adequate, and therefore could be used for prediction of the blend gasoline properties.
\end{abstract}

Keywords: Gasoline Blends, Modeling, Petroleum Refining, Octane Number, Reid Vapor Pressure, Multivariate Regression

\section{Introduction}

Crude petroleum in its natural state has little or no use, though it remains an essential source of energy affecting nearly every aspect of our modern lifestyle; it has to be refined in a refinery to different useful products. The refining process aims to maximize the value added by separating the crude oil using different physical and chemical processes into both intermediate products which can serve as feedstock to other downstream processes and finished products, including transportation fuels [1]. Some of the products are Liquefied Petroleum Gas (LPG), Straight Run Naphtha (SRN), Straight Run Gasoline (SRG), Kerosene, Gasoline or Premium Motor Spirit (PMS), Light Cycle Oil (LCO), Heavy Gas Oil (HGO), Reformates, Alkylates, amongst others. Of these products, PMS is the most important as it serves as fuel for most automotive engines which has proliferated because of the advancement in technology.

The naphthas are gasoline boiling range materials; they usually are sent to upgrading units (for octane improvement, sulfur control, etc.) and then to gasoline blending pool. The distillates, including kerosene, usually undergo further treatment and then are blended to jet fuel, diesel and home heating oil. The gas oils go to conversion units, where they are broken down into lighter (gasoline, distillate) streams. Finally, the residual oil (or bottoms) is routed to other conversion units or blended to heavy industrial fuel and/or asphalt. The bottoms have relatively little economic value - indeed lower value than the crude oil from which they come. Most modern refineries convert, or upgrade, the low-value heavy ends into more valuable light products (gasoline, jet fuel, diesel fuel, etc.).

Conversion processes carry out chemical reactions that fracture ("crack") large, high-boiling hydrocarbon molecules (of low economic value) into smaller, lighter molecules suitable, after further processing, for blending to gasoline, jet fuel, diesel fuel, petrochemical feedstocks and other high-value light products. Conversion units form the essential core of modern refining operations because they enable the refinery to achieve high yields of transportation fuels and 
other valuable light products, provide operating flexibility for maintaining light product output in the face of normal fluctuations in crude oil quality, and permit the economic use of heavy, sour crude oils [1-4].

Heavy gas oil from crude distillation is converted to light gases, petrochemical feedstock, gasoline blendstock (Fluid Catalytic Cracking (FCC) naphtha) and diesel fuel blendstock (light cycle oil) in the FCC process which employs zeolite as catalyst and operate at high temperature and low pressure. Distillates and heavy gas oils from crude distillation is converted in the hydrocracking unit to light gases, petrochemical feedstocks, gasoline and diesel fuel blendstocks The hydrocracking process is a catalytic process and operates at moderate temperature and high pressure.

Upgrading processes carry out chemical reactions that combine or re-structure molecules in low-value streams to produce higher-value streams, primarily high-octane, low sulphur gasoline blendstock. The upgrading processes of primary interest all employ catalysts, involve small hydrocarbon molecules, and apply to gasoline production. Some important upgrading processes are catalytic reforming in which catalytic reactions are carried out on straight run naphtha from crude distillation to increase the octane number of this stream and obtain premium, high-octane blendstock called reformate; alkylation which combines light olefins (primarily $\mathrm{C}_{4}$ and some $\mathrm{C}_{3}$ ) with isobutane to produce a high octane gasoline blendstock called alkylate; isomerization rearranges the low-octane $\mathrm{C}_{5}$ and $\mathrm{C}_{6}$ normal paraffin molecules in light straight run naphtha to corresponding higher-octane $\mathrm{C}_{5}$ and $\mathrm{C}_{6}$ iso-paraffins thereby significantly increasing the octane of the resulting naphtha stream (isomerate) and making it a valuable gasoline blendstock and Etherification combines $\mathrm{C}_{4}$ and/or $\mathrm{C}_{5}$ olefins produced by FCC plants with a purchased alcohol (methanol or ethanol) to produce an ether (a class of oxygen-containing organic compounds). Ethers are premium gasoline blendstocks, with very high octane and other desirable blending properties [1].

Gasoline which is a complex mixture of hydrocarbons contains paraffins, olefins, napthenes and aromatics was originally discarded as a by-product of kerosene production but its ability to vaporize at low temperatures makes it useful as a fuel for many machines. Gasoline contains hydrocarbons having boiling points in the range between $30^{\circ} \mathrm{C}$ to $215^{\circ} \mathrm{C}$. Gasoline was first produced initially by atmospheric distillation but the product obtained from this process had low qualities like the Research Octane Number (RON); which is an indication of the knock resistance of the gasoline in engines, and the volume obtained could not meet up with increasing demand. This dearth led to increased research into production of gasoline from other less commercial refinery products in several chemical processes and an attendant improvement in refinery complexity.

The ever increasing demand for gasoline makes it imperative to ensure that this product is readily available in the demanded volume while ensuring that its quality and specifications needed for effective performance in car engines is not compromised. The different refinery processes produce different products in different volumes and with different qualities and these different products have to be mixed optimally in the right volumes to obtain a product with desired properties in a blending process. Gasoline blending is the mechanical mixing of gasoline blending components streams to obtain various grades of gasoline and its very important to refinery economics as blending reduces property giveaway [5-8]. PMS blending is a very important part of refinery operations. Due to a large volume of the product, it is of pertinent importance to blend gasoline at the lowest possible cost, while satisfying quality constraints [9-11].

Seven most commonly employed refinery streams (cuts) in the gasoline production are: fluidized catalytic cracking (FCC), reforming (REF), isomerization (ISO), alkylation (ALK) and dimersol (DIM), together with the butane's fraction $\left(\mathrm{C}_{4}\right)$ and oxygenate additives such as MTBE or ethanol. These components as well as the ranges of their volumetric content in the blends and of their RON values are presented in Table $1[9,10]$.

Table 1. Gasoline components employed for the blends preparation

\begin{tabular}{llllll}
\hline Fraction & $\begin{array}{l}\text { Min } \\
\text { Vol \% }\end{array}$ & $\begin{array}{l}\text { Max } \\
\text { Vol \% }\end{array}$ & $\begin{array}{l}\text { Min } \\
\text { RON }\end{array}$ & $\begin{array}{l}\text { Max } \\
\text { RON }\end{array}$ & $\begin{array}{l}\text { Typical } \\
\text { RON }\end{array}$ \\
\hline FCC & 6.6 & 100.0 & 92.5 & 94.0 & 93.4 \\
REF & 0.0 & 54.4 & 98.2 & 103.6 & 101.4 \\
ISO & 0.0 & 32.0 & 77.5 & 86.2 & 84.5 \\
ALK & 0.0 & 20.7 & 93.3 & 94.7 & 94.0 \\
DIM & 0.0 & 14.8 & 93.8 & 97.6 & 95.0 \\
C 4 & 0.0 & 7.4 & - & - & 92.0 \\
Ethanol & 0.0 & 10.0 & - & - & 116.0 \\
\hline
\end{tabular}

Gasoline revenues accounts for a good share of the profitability of refineries. Mendez et al. [12] reported that gasoline production often yields $60-70 \%$ of a typical refinery's total revenue. The octane number of gasoline is an indication of its quality and a higher octane rating gasoline is more desirable and more expensive than a lower octane rating gasoline. It is therefore economically desirable to blend to get a desired optimum gasoline with favorable good price and also to improve the quality of the gasoline.

PMS blending could be tedious and time consuming. Lots of experiments are needed to determine the individual properties of the blend components and that of the final PMS and these components could be as over 100 in some cases $[13,14]$. Given a set of existing data, the blend behavior of the gasoline components can be predicted by representing the process via a mathematical model [15]. Mathematical model for gasoline blending is the mathematical presentation of gasoline blend components to allow investigation of key properties of the system and prediction of future outcomes to be carried out [16]. Without accurate blending correlations, any attempt to blend different gasoline cuts can be expected to achieve non-optimum results [17]. Hence, there is need to obtain a mathematical model to effectively predict these properties of the PMS from various blendstocks in order to

- improve refinery profitability 
- reduce property giveaway

- reduce the cost of performing several experiments to determine PMS components and product properties thereby saving costs

- reduce the time needed to blend a batch and ensure continual availability of gasoline [18].

Research and Motor Octane numbers (RON, MON), Reid Vapor Pressure (RVP) and Specific Gravity (SG) are the main quality characteristic of the gasoline, as they provide a sensitive indication of the anti-knocking behavior of the fuel. The higher the octane number the better the gasoline resists detonation and the smoother the engine runs. Other important technological properties of the commercial gasoline are ASTM distillation points, and sulfur content. These properties are monitored during production to ensure the required technological and environmental quality level of the final gasoline is gained. Although the final gasoline has to meet all the product specification, RON and MON are considered to be the most important. The Reid Vapour Pressure is an indication of the volatility of gasoline in internal combustion engines while the Specific Gravity gives an indication of how heavy the product is. RON and MON values, as well as most of the gasoline properties, blend in non-ideal fashion, i.e. they depend non-linearly on the mixture composition. Therefore algorithms more complex than linear combination are necessary for the reliable prediction. There is a marked interest in refineries to utilize algorithms for the prediction of the octane rating of the gasoline blends [19].

Numerous studies in the past have attempted to mathematically describe the octane number as a function of the gasoline composition. Schoen and Mrstik [20] developed a graphical correlation for predicting octane numbers of blends as a series of binary systems based on the octane rating and volumetric olefin contents of the two components being blended. The blended octane number yields different values depending upon the order of calculation. Stewart [21] refined this method to be applicable to multicomponent blends yielding more self-consistent results. Stewart's correlation also required the octane rating and volume percent olefins of the components being blended. Auckland and Charnock [4] developed a blending index to blend octane number linearly. The blending index is a hypothetical value obtained by extrapolating from the octane rating at a given concentration to an octane rating at $100 \%$ concentration of component. However, obtaining blend values by blending the blending indices linearly is analogous to obtaining the molar property of a real solution by a linear combination of the partial molar properties of its components. Since the partial molar property depends on the composition, so does the blending index. Therefore, the usage of this approach is limited. The index method can only be used to find the blending value of a component at a particular composition and cannot be used to predict its blending values in other mixtures.

Rusin et al. [22] presented a rather complicated transformation method for estimating the octane number of gasoline blends from the octane ratings of the components, their concentrations, and contents of olefins, aromatics and paraffins. The method consists of three steps: (a) transformation of component properties (b) linear blending of these transformed properties, and (c) inverse transformation of the results. This method is similar to the blending index method. Due to the back and forth transformation, this method may also cause inconsistency in data transformation between these three steps. Healy et al [10] correlated gasoline component blending with differences in octane level and hydrocarbon type among components. However, if the equation of Healy et al. is used to predict the blending behavior of new components, unreasonable blending values may be obtained, especially if the hydrocarbon type or octane number of the new component is outside the range of the component previously tested [23].

An interesting equation was proposed by Morris et al. [23] for describing nonlinear gasoline blending behavior as follows:

$$
\text { octane number }=x_{1} a_{1}+x_{2} a_{2}+b_{12} x_{1} x_{2}
$$

where $\mathrm{a}_{\mathrm{i}}$ and $\mathrm{x}_{\mathrm{i}}$ are the octane number and the volume fraction of component $\mathrm{i}$, respectively and $\mathrm{b}_{12}$ is the interaction coefficient for components 1 and 2 .

Equation (1), which represents a simple excess octane number function, is quite effective in correlating the octane numbers of gasoline blends. However, there are some disadvantages of using this model to describe gasoline blending behavior. First, the parameter $b_{12}$ is an empirical constant, which depends on the characteristics of components 1 and 2 . The interaction parameter $b_{12}$ not only depends on the component types, but it also depends on the octane levels and octane differences. The values of $b_{12}$ can vary from large negative to large positive ones and the interaction parameter $b_{12}$ must be changed if the component characteristics change. The set of binary parameters obtained from equation (1) can only be used for the specific set of components where the parameters were derived. Therefore it would be very difficult to generalize these interaction parameters as a function of these properties for the purpose of prediction. A second disadvantage is that when new components are added to the gasoline pool, new interaction parameters are required to describe the behavior of the new component with the present components. Because it is non-trivial to run a blending study, it is very costly to run additional blending studies whenever there are new components to be blended into the gasoline pool.

Pasadakis et al. [24] used Artificial Neural Network (ANN) models have to determine the RON of gasoline blends produced in a Greek refinery. The developed ANN models use as input variables the volumetric content of seven most commonly used fractions in the gasoline production and their respective RON values. The predicting ability of the models, in the multi-dimensional space determined by the input variables, was thoroughly examined in order to assess their robustness. Based on the developed ANN models, the effect of each gasoline constituent on the formation of the blend RON value was revealed.

Zahed et al. [25] proposed a model with five independent 
variables for predicting the octane number of gasoline blends. The variables of the model can be regressed so that the model works well for the blends used in the regression but it will still perform poorly for other blends. The five variables derived from this model are internally inconsistent. The octane number of $n$-heptane predicted from this model is 108.77 versus the defined value of zero. Similarly, the octane number of iso-octane predicted from this model is -108.95 versus the defined value of 100 . The set of variables obtained from this model can only be used for this specific set of components within the same range of compositions where the variables were derived. The use of this model to predict the octane number of blends at other conditions will therefore be very unreliable.

Prasenjeet et al. [26] presented a model that predicts the octane numbers of a wide variety of gasoline process streams and their blends including oxygenates based on detailed composition. The octane number is correlated to a total of 57 hydrocarbon lumps measured by gas chromatography. The model is applicable to any gasoline fuel regardless of the refining process it originates from. It is based on the analysis of 1471 gasoline fuels from different naphtha process streams such as reformates, cat-naphthas, alkylates, isomerates, straight runs, and various hydroprocessed naphthas. The model predicts the octane number within a standard error of 1 number for both the research and motor octane numbers.

This study has been carried out with the objective to develop a mathematical model for blending gasoline and employ the model to predict predicting the research octane number, reid vapour pressure and the specific gravity of gasoline blends. This work attempts to develop a model for predicting the blend properties of various gasoline cuts obtained from the Port Harcourt Refinery Company Limited Nigeria.

\section{Methodology}

Figure 1 represents a typical industrial blending process employed to produce a quality gasoline from various product streams. Five PMS blending data (Table 2) for gasoline produced from four different blend cuts: Straight Run Gasoline (SRN), Straight Run Naphtha (SRN), Reformate (REF) and Fluidized Catalytically Cracked Gasoline (FCCG) were obtained by the Production Programming and Quality Control (PPQC) department of the Port Harcourt Refining Company (PHRC), Nigeria. The raw gasoline cut qualities (RON, RVP and SG) were determined by the Quality Control department prior to blending using standard ASTM analytical methods.

The Production Programming Unit of the PPQC in PHRC utilizes linear volumetric blending formula in formulating gasoline blendstocks. The formula is presented below

$$
R O N_{P M S}=\sum_{i=1}^{4} x_{i} \times R O N_{i}
$$

where $R O N_{P M S}$ represents the final RON of the PMS

$x_{i}$ represents the volumetric ratio of the blend components

$R O N_{i}$ represents the RON of the blend components

$$
x_{i}=\frac{\text { Volume of component } i}{\text { Total volume of PMS mixture }}
$$

For the modeling equation, the volume fraction of each cut (FCCG, SRN, SRG and REF) in the resulting PMS blend were taken as the dependent variables and represented by $x_{1}, x_{2}$, $x_{1}$, and $x_{4}$ respectively, while the dependent variable $y$ represents the resulting particular PMS properties being modeled (RON, RVP or SG). A DataFit regression package from Oakdale Engineering Software was used to fit the data obtained [27].

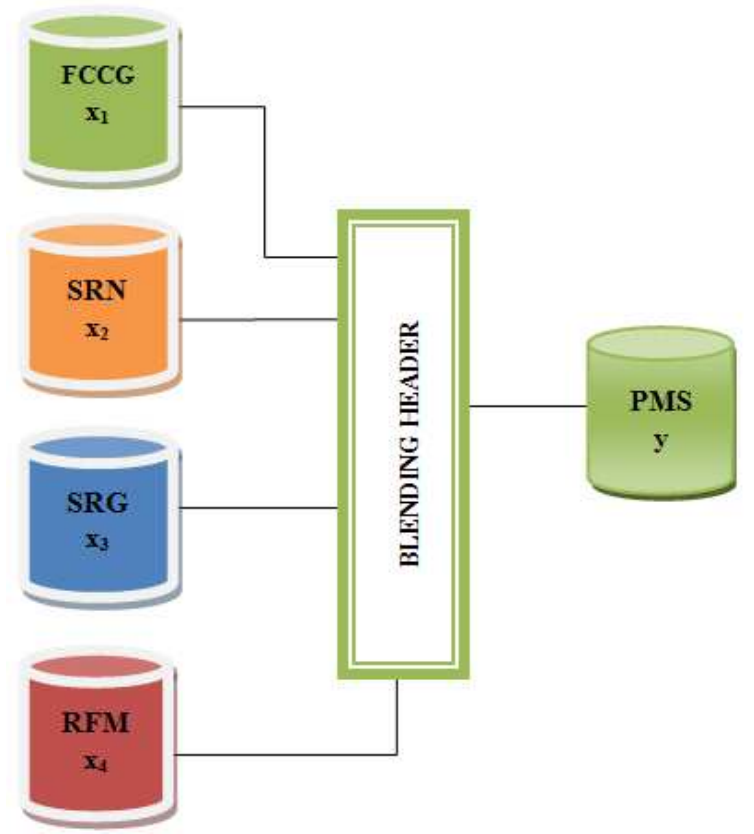

Figure 1. Diagrammatic representation of the gasoline blender

Table 2. PMS Blend data

\begin{tabular}{lllllll}
\hline Content & Tank & S/ & Volume, & SG & RVP & RON \\
& & No & L & & & \\
\hline Fluid & 52 TK03 & 1 & 7800 & 0.7604 & 0.46 & 95.00 \\
Catalytic & & 2 & 7700 & 0.7601 & 0.56 & 95.10 \\
Cracking & & 3 & 7700 & 0.7584 & 0.61 & 94.7 \\
Gasoline & & 4 & 8000 & 0.7589 & 0.47 & 94.8 \\
(FCCG) & & 5 & 7500 & 0.7594 & 0.48 & 94.70 \\
Straight & 51 TK01 & 1 & 2200 & 0.7697 & 0.15 & 60.00 \\
Run & & 2 & 3100 & 0.7703 & 0.15 & 61.00 \\
Naphta & & 3 & 3500 & 0.7708 & 0.14 & 61.0 \\
(SRN) & & 4 & 3000 & 0.7708 & 0.14 & 61.0 \\
& & 5 & 3800 & 0.7682 & 0.06 & 64.60 \\
Straight & 52 TK01 & 1 & 2300 & 0.6519 & 1.17 & 73.50 \\
Run & & 2 & 1200 & 0.6599 & 1.05 & 76.00 \\
Gasoline & & 3 & 500 & 0.6585 & 1.11 & 75.0 \\
(SRG) & & 4 & 1000 & 0.6549 & 1.11 & 74.0 \\
& & 5 & 1200 & 0.6658 & 0.99 & 88.50 \\
Reformate & 52 TK02 & 1 & 7700 & 0.7534 & 0.29 & 95.90 \\
(REF) & & 2 & 8000 & 0.7512 & 0.28 & 96.30 \\
& & 3 & 8300 & 0.7568 & 0.40 & 97.0 \\
& & 4 & 8000 & 0.7579 & 0.36 & 95.6 \\
& & 5 & 7500 & 0.7560 & 0.32 & 96.00 \\
TOTAL VOLUME & & $\mathbf{2 0 0 0 0}$ & & & \\
\hline
\end{tabular}




\section{Results and Discussion}

In this study, we employ the regression model technique for the situation where we have measured five responses $y_{1}, y_{2}, \ldots$ $y_{5}$ and the same set of 4 predictors $x_{1} \ldots x_{4}$ on each sample unit. Each response follows its own regression model, as an example, for the nonlinear multivariable model we have the following equations:

$$
\begin{gathered}
\mathrm{y}_{1}=\mathrm{a}_{01}+\mathrm{a}_{11} \mathrm{x}_{1}+\ldots+\mathrm{a}_{41} \mathrm{x}_{4}+\varepsilon_{1} \\
\mathrm{y}_{2}=\mathrm{a}_{02}+\mathrm{a}_{12} \mathrm{x}_{1}+\ldots+\mathrm{a}_{42} \mathrm{x}_{4}+\varepsilon_{2} \\
\ldots \\
\ldots \\
\mathrm{y}_{5}=\mathrm{a}_{05}+\mathrm{a}_{15} \mathrm{x}_{1}+\ldots+\mathrm{a}_{45} \mathrm{x}_{4}+\varepsilon_{5}
\end{gathered}
$$

where $\varepsilon=\left(\varepsilon_{1}, \ldots ., \varepsilon_{5}\right)$ are the errors associated with different responses on the same sample unit, which have different variances and may be correlated.

Knowing from the basis of definition that $x_{4}$ could be expressed as a function of other independent variables, (4) could be simplified further to yield (5). The dependent variables were obtained from the given blend data (Table 2) using (3). The five sets of dependent variables corresponding to the values of the blend properties given in the data. Similar procedure have been observed for the three parameters being modeled, the RON, RVP and SG. Table 3 shows the typical data employed for regression analysis based on the RON blend data.

Table 3. Regression analysis data for RON blend data

\begin{tabular}{ccccc}
\hline $\mathbf{Y}$ & $\mathbf{x}_{\mathbf{1}}$ & $\mathbf{x}_{\mathbf{2}}$ & $\mathbf{x}_{\mathbf{3}}$ & $\mathbf{x}_{\mathbf{4}}$ \\
\hline 89.0965 & 0.375 & 0.19 & 0.06 & 0.375 \\
89.01 & 0.4 & 0.15 & 0.05 & 0.4 \\
89.2645 & 0.385 & 0.175 & 0.025 & 0.415 \\
89.1485 & 0.385 & 0.155 & 0.06 & 0.4 \\
89.024 & 0.39 & 0.11 & 0.115 & 0.385 \\
\hline
\end{tabular}

Amongst several mathematical models worked upon, particularly noteworthy and hereby reported are the following model equations:

Model 1

$$
y=a+b x_{1}+c x_{2}+d x_{3}
$$

and Model 2

$$
y=a_{0}+a_{1} \exp \left(x_{1}\right)+a_{2} \exp \left(x_{2}\right)+a_{3} \exp \left(x_{3}\right)
$$

The key results of the regression analysis obtained with the aid of the Datafit Regression Package for all the blend properties considered in this study are summarized in Table 4.

\begin{tabular}{|c|c|c|c|c|c|c|c|}
\hline \multirow{2}{*}{ Blend property } & \multirow{2}{*}{ Model equation } & \multicolumn{4}{|c|}{ Regression coefficients* } & \multirow{2}{*}{$\mathbf{R}^{2}$} & \multirow{2}{*}{ Standard error, $\varepsilon$} \\
\hline & & $a, a_{0}$ & $b, a_{1}$ & $c, a_{2}$ & $d, a_{3}$ & & \\
\hline \multirow[t]{2}{*}{ RON } & Model 1 & 80.33 & 90.33 & 90.47 & 97.01 & 0.994 & 0.016 \\
\hline & Model 2 & 119.2 & -11.5 & -5.79 & -6.06 & 0.987 & 0.024 \\
\hline \multirow[t]{2}{*}{ RVP } & Model 1 & -1.35 & -0.44 & 0.50 & 2.47 & 0.883 & 0.022 \\
\hline & Model 2 & 9.03 & -2.59 & -2.48 & -1.79 & 0.853 & 0.025 \\
\hline \multirow[t]{2}{*}{ SG } & Model 1 & 0.82 & 0.77 & 0.62 & 0.70 & 0.988 & 0.0009 \\
\hline & Model 2 & 0.64 & 0.084 & 0.06 & -0.07 & 0.988 & 0.0009 \\
\hline
\end{tabular}
The regression coefficients corresponding to each model equation are shown together with the values of the coefficient of determination $\left(\mathrm{R}^{2}\right)$, and the standard error of estimate $(\varepsilon)$.

Table 4. Regression analysis values for Models 1 and 2

* a, b, c, d correspond to Model 1, while $a_{0}, a_{1}, a_{2}, a_{3}$ Model 2

As can be seen from Table 4, the coefficient of determination $\mathrm{R}^{2}$ for the RON data using Model 1 has a value of 0.994 with a standard error of estimate of 0.016 . This implies that the data obtained from PHRC closely fitted to that obtained from the model generated and that 99.4 percent of the data set is accounted for by Model 1. Similar results obtained with the aid of Model $2\left(\mathrm{R}^{2}=0.988, \varepsilon=0.024\right)$ confirmed the applicability of this exponential model in describing the given set of data. It follows that both the nonlinear multivariate model equation and the exponential equation are very suitable for predicting the behavior of RON of gasoline blends. Increasing research into the motor and research octane number of gasoline has been caused ever since the use of Lead as an additive to motor fuel in the form of tetraethyl lead had been progressively phased-out worldwide due to emission problem. The anti knock index (AKI) is an average value of RON and
MON.

A graphical representation comparing the industry data from PHRC and that predicted from Model 1 is shown in Fig. 2. Here, data and model plots are made on one graph; the trend line of data obtained from PHRC is shown in dotted lines while that predicted by the model is shown in thickened line. A visual inspection shows that there is a close correlation between the raw data and the model predicted data.

Similar trends were observed upon analysis of the regression data for the other parameters, reid vapor pressure and specific gravity, as can be seen from Table 4 and Figs 3 and 4. Sufficiently high $\mathrm{R}^{2}$ values ( 0.883 and 0.853 for RVP using Models 1 and 2 respectively) with still higher values of this statistical parameter $(0.988$ and 0.988 for SG models 1 and 2) further buttressed the fact that the proposed models can adequately be employed for the target purpose. 

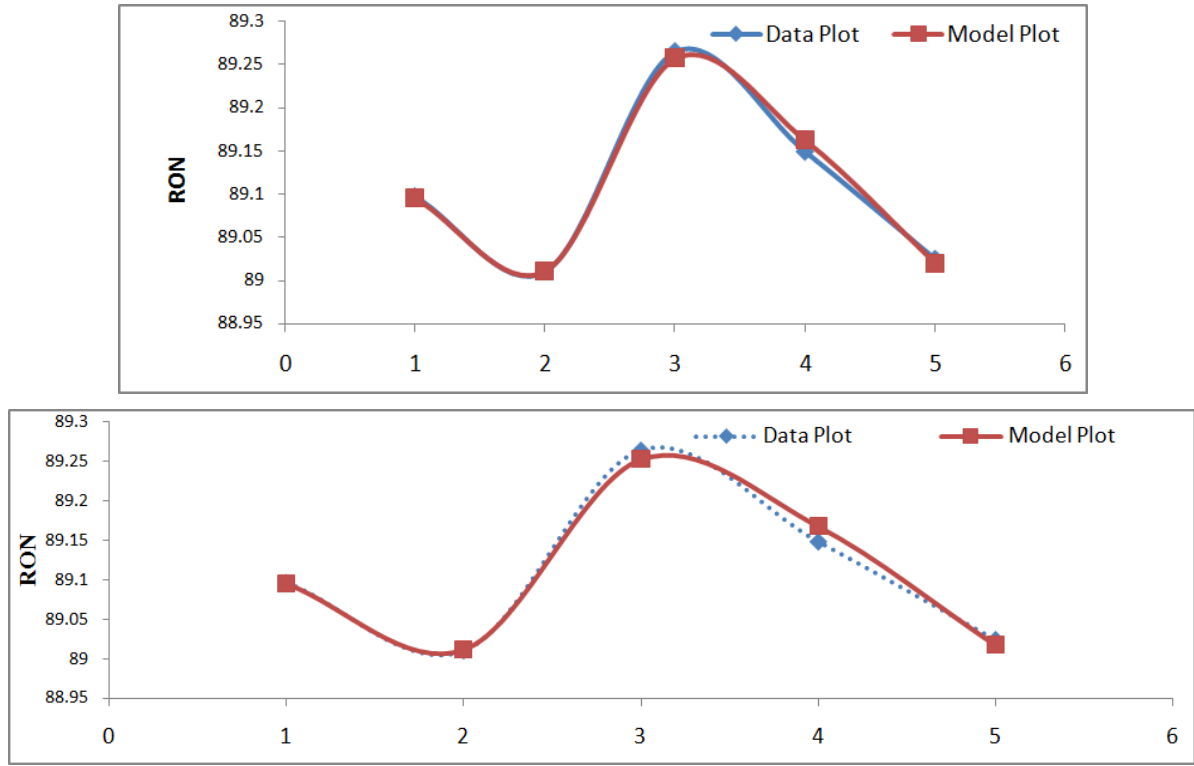

Figure 2. Plot of RON fit curve for model 1 upward and model 2 downward.

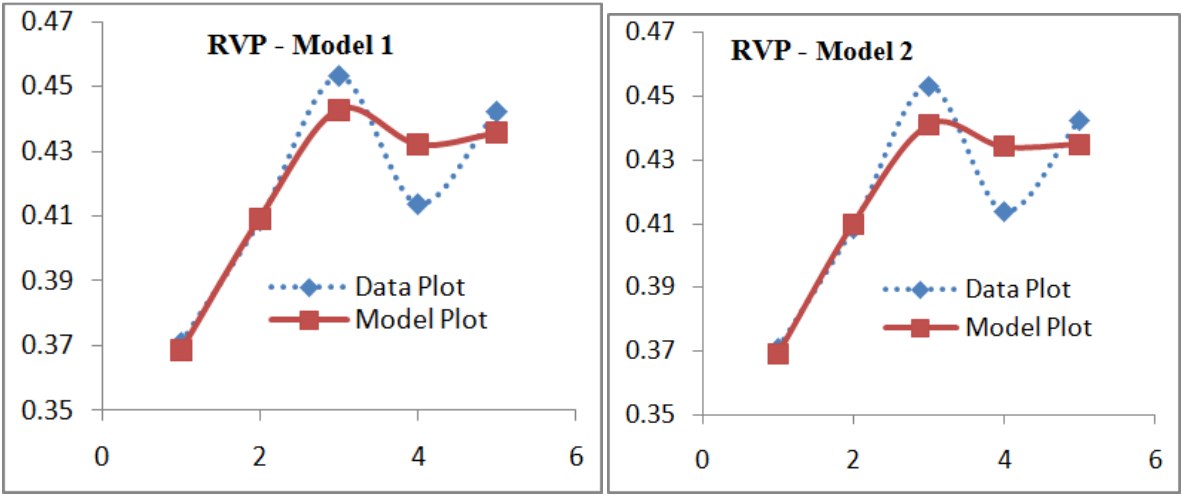

Figure 3. Plot of RVP fit curve for model 1 left and model 2 right.
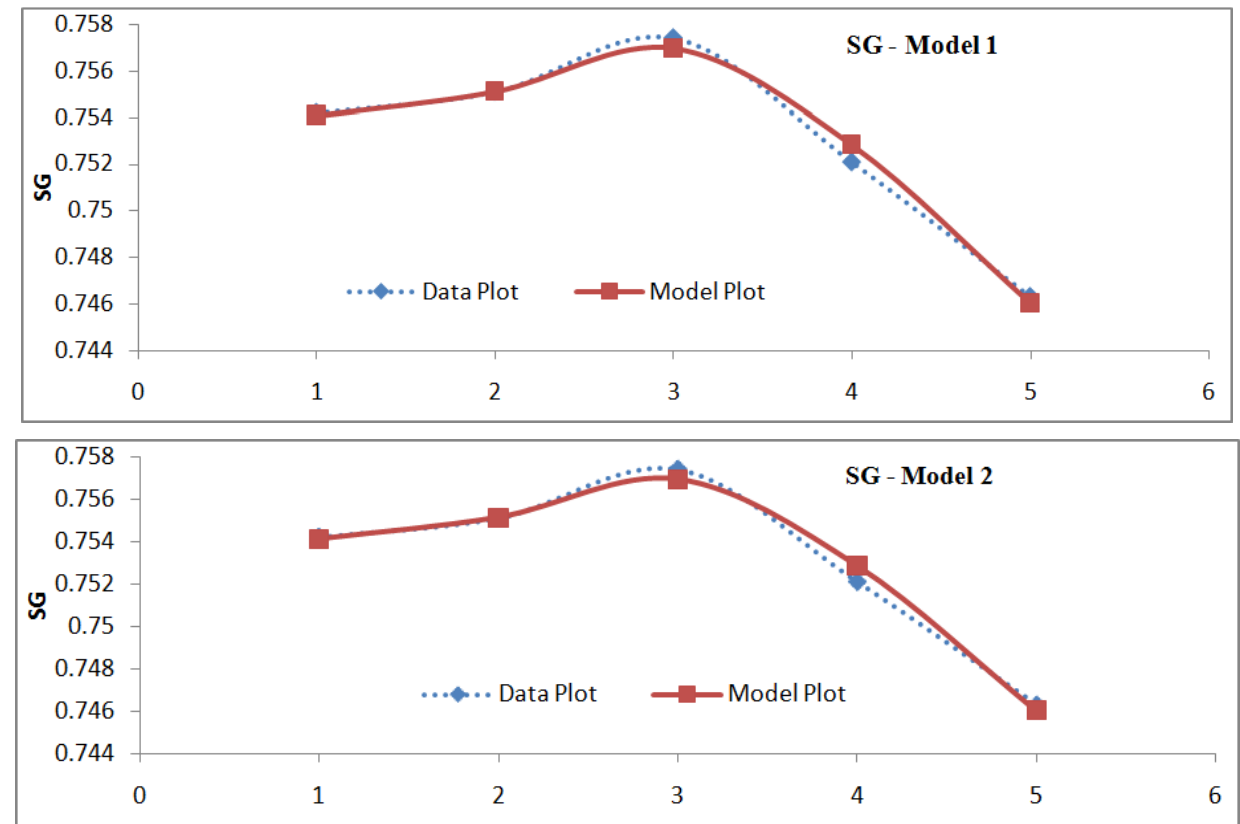

Figure 4. Plot of SG fit curve for model 1 upward and model 2 downward. 


\section{Conclusion}

Model equations have been put forward to predict final properties, in particular the research octane number, reid vapor pressure and specific gravity of the gasoline resulting from blending of various gasoline cuts. The results of the regression analysis showed that the nonlinear multivariable models proposed gave a good fit as evidenced by the value of the coefficient of determination $\mathrm{R}^{2}=0.988 \& 0.994$ for the research octane number RON, $0.853 \& 0.883$ for the reid vapor pressure RVP and 0.988 for SG. The scope of the study could be expanded to include other refinery gasoline blend components like butane, alkylate, dimate, as well as "octane booster" gasoline additives including ethyl tert-butyl ether (ETBE) and methyl tert-butyl ether (MTBE), isooctane, toluene, and oxygenates where they are being utilized.

\section{Acknowledgements}

The contribution of the Management \& Staff of the Port Harcourt Refinery Company (PHRC), Port Harcourt, NIGERIA to the success of this paper is gratefully acknowledged, especially for the raw data on gasoline blends.

\section{Appendix}

RON Fit Information for Model 1

\begin{tabular}{|c|c|c|c|c|c|}
\hline \multicolumn{6}{|c|}{ Model Definition: $\quad \mathrm{y}=\mathrm{ax}_{1}+\mathrm{bx}_{2}+\mathrm{cx}_{3}+\mathrm{dx}_{4}$} \\
\hline \multicolumn{3}{|c|}{ Number of observations $=5$} & \multicolumn{3}{|c|}{ Average Residual $=-8.5265128291212 \mathrm{E}-15$} \\
\hline \multicolumn{3}{|c|}{ Number of missing observations $=0$} & \multicolumn{3}{|c|}{ Residual Sum of Squares (Absolute) $=2.56784042317984 \mathrm{E}-04$} \\
\hline \multicolumn{3}{|c|}{ Solver type: Nonlinear } & \multicolumn{3}{|c|}{ Residual Sum of Squares (Relative) $=2.56784042317984 \mathrm{E}-04$} \\
\hline \multicolumn{3}{|c|}{ Nonlinear iteration limit $=250$} & \multicolumn{3}{|c|}{ Standard Error of the Estimate $=1.60244825912721 \mathrm{E}-02$} \\
\hline \multicolumn{3}{|c|}{ Diverging nonlinear iteration limit $=10$} & \multicolumn{3}{|c|}{ Coefficient of Multiple Determination $\left(\mathrm{R}^{\wedge} 2\right)=0.9940174678$} \\
\hline \multicolumn{3}{|c|}{ Number of nonlinear iterations performed $=11$} & \multicolumn{3}{|c|}{ Proportion of Variance Explained = 99.40174678\% } \\
\hline \multicolumn{3}{|c|}{ Residual tolerance $=0.0000000001$} & \multicolumn{3}{|c|}{ Adjusted coefficient of multiple determination $\left(\mathrm{Ra}^{\wedge} 2\right)=0.9760698712$} \\
\hline \multicolumn{3}{|c|}{ Sum of Residuals $=-4.2632564145606 \mathrm{E}-14$} & \multicolumn{3}{|c|}{ Durbin-Watson statistic $=3.18736483829897$} \\
\hline \multicolumn{6}{|c|}{ Regression Variable Results } \\
\hline Variable & Value & Standard Error & t-ratio & $\operatorname{Prob}(\mathrm{t})$ & \\
\hline A & 80.3334859739025 & 0.932619716219116 & 86.13745193 & 0.00739 & \\
\hline B & 90.3313258441462 & 0.354588591414152 & 254.7496677 & 0.0025 & \\
\hline $\mathrm{C}$ & 90.4714651835739 & 0.463398896931756 & 195.2345286 & 0.00326 & \\
\hline $\mathrm{D}$ & 97.0094259621047 & 0.825670550622306 & 117.4916871 & 0.00542 & \\
\hline \multicolumn{6}{|c|}{$99 \%$ Confidence Intervals } \\
\hline Variable & Value & $99 \%(+/-)$ & Lower Limit & Upper Limit & \\
\hline A & 80.3334859739025 & 59.3682395852184 & 20.9652463886841 & 139.70172555 & \\
\hline B & 90.3313258441462 & 22.5722232579464 & 67.7591025861998 & 112.90354910 & \\
\hline $\mathrm{C}$ & 90.4714651835739 & 29.4988152814333 & 60.9726499021406 & 119.97028046 & \\
\hline $\mathrm{D}$ & 97.0094259621047 & 52.5601230762394 & 44.4493028858653 & 149.56954903 & \\
\hline \multicolumn{6}{|c|}{ Variance Analysis } \\
\hline Source & DF & Sum of Squares & Mean Square & F Ratio & $\operatorname{Prob}(\mathrm{F})$ \\
\hline Regression & 3 & 0.04266551595768 & 0.01422183865256 & 55.38443325 & 0.09838 \\
\hline Error & 1 & $2.56784042317984 \mathrm{E}-04$ & $2.56784042317984 \mathrm{E}-04$ & & \\
\hline Total & 4 & 0.042922299999998 & & & \\
\hline
\end{tabular}


RVP Fit Information Model 1

\begin{tabular}{|c|c|c|c|c|c|}
\hline \multicolumn{6}{|c|}{ Equation ID: Model 1} \\
\hline \multicolumn{6}{|c|}{ Model Definition: $\mathrm{y}=\mathrm{ax}_{1}+\mathrm{bx}_{2}+\mathrm{cx}_{3}+\mathrm{dx}_{4}$} \\
\hline \multicolumn{3}{|c|}{ Number of observations $=5$} & \multicolumn{3}{|c|}{ Average Residual $=-1.88737914186277 \mathrm{E}-16$} \\
\hline \multicolumn{3}{|c|}{ Number of missing observations $=0$} & \multicolumn{3}{|c|}{ Residual Sum of Squares (Absolute) $=4.84349755480196 \mathrm{E}-04$} \\
\hline \multicolumn{3}{|c|}{ Solver type: Nonlinear } & \multicolumn{3}{|c|}{ Residual Sum of Squares (Relative) $=4.84349755480196 \mathrm{E}-04$} \\
\hline \multicolumn{3}{|c|}{ Nonlinear iteration limit $=250$} & \multicolumn{3}{|c|}{ Standard Error of the Estimate $=2.20079475526501 \mathrm{E}-02$} \\
\hline \multicolumn{3}{|c|}{ Diverging nonlinear iteration limit $=10$} & \multicolumn{3}{|c|}{ Coefficient of Multiple Determination $\left(\mathrm{R}^{\wedge} 2\right)=0.883210643$} \\
\hline \multicolumn{3}{|c|}{ Number of nonlinear iterations performed $=11$} & \multicolumn{3}{|c|}{ Proportion of Variance Explained $=88.3210643 \%$} \\
\hline \multicolumn{3}{|c|}{ Residual tolerance $=0.0000000001$} & \multicolumn{3}{|c|}{ Adjusted coefficient of multiple determination $\left(\mathrm{Ra}^{\wedge} 2\right)=0.5328425722$} \\
\hline \multicolumn{3}{|c|}{ Sum of Residuals $=-9.43689570931383 \mathrm{E}-16$} & \multicolumn{3}{|c|}{ Durbin-Watson statistic $=3.18736483829746$} \\
\hline \multicolumn{6}{|c|}{ Regression Variable Results } \\
\hline Variable & Value & Standard Error & t-ratio & \multicolumn{2}{|l|}{$\operatorname{Prob}(\mathrm{t})$} \\
\hline A & -1.34885700506242 & 1.28085544629671 & -1.053090736 & \multicolumn{2}{|l|}{0.48354} \\
\hline B & -0.437995410645829 & 0.486990271178 & -0.899392527 & \multicolumn{2}{|l|}{0.53369} \\
\hline $\mathrm{C}$ & 0.503133312444704 & 0.636429823024969 & 0.790555839 & \multicolumn{2}{|l|}{0.57413} \\
\hline $\mathrm{D}$ & 2.47296374594515 & 1.1339719750927 & 2.180797939 & \multicolumn{2}{|l|}{0.27371} \\
\hline \multicolumn{6}{|c|}{$99 \%$ Confidence Intervals } \\
\hline Variable & Value & $99 \%(+/-)$ & Lower Limit & \multicolumn{2}{|c|}{ Upper Limit } \\
\hline A & -1.34885700506242 & 81.536055572633 & -82.8849125776954 & \multicolumn{2}{|c|}{80.1871985675705} \\
\hline B & -0.437995410645829 & 31.0005831875135 & -31.4385785981594 & \multicolumn{2}{|c|}{30.5625877768677} \\
\hline $\mathrm{C}$ & 0.503133312444704 & 40.5135314592119 & -40.0103981467672 & \multicolumn{2}{|c|}{41.0166647716566} \\
\hline $\mathrm{D}$ & 2.47296374594515 & 72.1858210044637 & -69.7128572585185 & \multicolumn{2}{|c|}{74.6587847504088} \\
\hline \multicolumn{6}{|c|}{ Variance Analysis } \\
\hline Source & DF & Sum of Squares & Mean Square & F Ratio & $\operatorname{Prob}(\mathrm{F})$ \\
\hline Regression & 3 & $3.6628582445198 \mathrm{E}-03$ & $1.22095274817327 \mathrm{E}-03$ & \multirow[t]{3}{*}{2.52080802} & \multirow[t]{3}{*}{0.4265} \\
\hline Error & 1 & 4.84349755480196E-04 & 4.84349755480196E-04 & & \\
\hline Total & 4 & 0.004147208 & & & \\
\hline
\end{tabular}

SG Fit Information for Model 2

\begin{tabular}{|c|c|c|c|c|c|}
\hline \multicolumn{6}{|c|}{ Equation ID: Model 2} \\
\hline \multirow{2}{*}{\multicolumn{3}{|c|}{$\begin{array}{l}\text { Model Definition: } \\
\text { Number of observations }=5\end{array}$}} & \multirow{2}{*}{\multicolumn{3}{|c|}{ Average Residual $=7.99360577730113 \mathrm{E}-16$}} \\
\hline & & & & & \\
\hline $\begin{array}{l}\text { Number of observations }=5 \\
\text { Number of missing observations }=0\end{array}$ & \multicolumn{2}{|c|}{ Number of missing observations $=0$} & \multicolumn{3}{|c|}{ Residual Sum of Squares (Absolute) $=-1.88737914186277 \mathrm{E}-16$} \\
\hline & \\
\hline \multicolumn{3}{|c|}{ Nonlinear iteration limit $=250$} & \multicolumn{3}{|c|}{$\begin{array}{l}\text { Residual Sum of Squares }(\text { Relative })=8.77507022601528 \mathrm{E}-07 \\
\text { Standard Error of the Estimate }=9.36753448139652 \mathrm{E}-04\end{array}$} \\
\hline \multicolumn{3}{|c|}{ Diverging nonlinear iteration limit $=10$} & \multicolumn{3}{|c|}{ Coefficient of Multiple Determination $\left(\mathrm{R}^{\wedge} 2\right)=0.9876247106$} \\
\hline \multicolumn{3}{|c|}{ Number of nonlinear iterations performed $=10$} & \multicolumn{3}{|c|}{ Proportion of Variance Explained $=98.76247106 \%$} \\
\hline \multicolumn{3}{|c|}{ Residual tolerance $=0.0000000001$} & \multicolumn{3}{|c|}{ Adjusted $\left(\mathrm{Ra}^{\wedge} 2\right)=0.9504988423$} \\
\hline \multicolumn{3}{|c|}{ Sum of Residuals $=3.99680288865056 \mathrm{E}-15$} & \multicolumn{3}{|c|}{ Durbin-Watson statistic $=3.24519825698429$} \\
\hline \multicolumn{6}{|c|}{ Regression Variable Results } \\
\hline Variable & Value & Standard Error & t-ratio & \multicolumn{2}{|l|}{$\operatorname{Prob}(t)$} \\
\hline a0 & 0.636780770242741 & 0.180899312307499 & 3.520083974 & \multicolumn{2}{|l|}{0.17621} \\
\hline a1 & $8.39111049388251 \mathrm{E}-02$ & 7.02630414986109E-02 & 1.194242423 & \multicolumn{2}{|l|}{0.44379} \\
\hline a2 & $6.00086191331493 \mathrm{E}-02$ & 0.042902232857076 & 1.39872951 & \multicolumn{2}{|l|}{0.39514} \\
\hline a3 & $-7.28034857759079 \mathrm{E}-02$ & $3.40478454804993 \mathrm{E}-02$ & -2.138269977 & 0.27849 & \\
\hline \multicolumn{6}{|c|}{$99 \%$ Confidence Intervals } \\
\hline Variable & Value & $99 \%(+/-)$ & Lower Limit & \multicolumn{2}{|c|}{ Upper Limit } \\
\hline $\mathrm{a} 0$ & 0.636780770242741 & 11.5155979732146 & -10.8788172029719 & \multicolumn{2}{|c|}{12.1523787434574} \\
\hline a1 & $8.39111049388251 \mathrm{E}-02$ & 4.47276956419783 & -4.388858459259 & 4.556680669 & \\
\hline $\mathrm{a} 2$ & $6.00086191331493 \mathrm{E}-02$ & 2.73104888809931 & -2.67104026896616 & 2.7910575072 & \\
\hline a3 & $-7.28034857759079 \mathrm{E}-02$ & 2.16740072367489 & -2.24020420945079 & 2.0945972378 & \\
\hline Variance An & & & & & \\
\hline Source & DF & Sum of Squares & Mean Square & F Ratio & $\operatorname{Prob}(F)$ \\
\hline Regression & 3 & 7.00304929773986E-05 & $2.33434976591329 \mathrm{E}-05$ & 26.60206364 & 0.14135 \\
\hline Error & 1 & $8.77507022601528 \mathrm{E}-07$ & $8.77507022601528 \mathrm{E}-07$ & & \\
\hline Total & 4 & $7.09080000000001 \mathrm{E}-05$ & & & \\
\hline
\end{tabular}




\section{References}

[1] MathPro, An introduction to petroleum refining and the production of ultra low sulfur gasoline and diesel fuel, the International Council of Clean Transportation (ICCT), 2011.

[2] C.Y. Jaja, Recent trends and patterns of gasoline consumption in Nigeria, Council for the Development of Social Science Research in Africa, pp. 159 - 177, 2010.

[3] J. Wodausch, Investigation and prediction of autoignition during hot start conditions, M.Sc. Thesis, Nelson Mandela Metropolitan University, 2009.

[4] M.H.T. Auckland and D.J. Charnock, The Development of Linear Blending Indices for Petroleum Properties, J. Inst. of Petroleum, 55(545), 322- 329, 1969.

[5] M.B. Celik, Experimental determination of suitable ethanol-gasoline blend rate at high compression ratio for gasoline engine, Appl. Thermal Engrng., .28, 396-404, 2008.

[6] A.E. Eiman, Improvement of gasoline octane number by blending gasoline with selective components, M.Sc Thesis, University of Technology, Republic of Iraq, 2008.

[7] M.M. Farsibaf, M. Golchinpour, and A. Barzegar, Global optimization in order to find blend composition of gasoline of desired octane number considering ethanol as octane-booster, 41st International Conference on Computers \& Industrial Engineering, 313 - 318, 2012.

[8] S. Fernando, Internal combustion engines, $\mathrm{PhD}$ Thesis, Department of Aerospace and Mechanical Engineering University of Notre Dame, Notre Dame, 1998.

[9] A. Hassan and Mourhaf, Correlation between the octane number of motor gasoline and its boiling range, J. King Saud Univ., Vol. 9, Eng .Sci. (2), pp. 311-318, 1996.

[10] Jr. W.C. Healy, C.W. Maassen, and R.T. Peterson, A new approach to blending octanes, API Division of Refining, 24th midyear meeting, New York, 1959.

[11] W.G. Lovell, J.M. Campbell, T.A. Boyd, Detonation characteristics of some aliphatic olefin hydrocarbons, Ind. Eng. Chem.. 555, 1931.

[12] C.A. Mendez, I.E. Grossmann and I. Harjunkoski, Optimization techniques for blending and scheduling of oil-refinery operations, Carnegie Mellon University Pittsburgh, U.S.A. 2011.

[13] D.S. Monder, Real-time optimization of gasoline blending with uncertain parameters, M.Sc Thesis, University of Alberta, Canada, 2001.
[14] G. Najafi, B. Ghodadiam, T. Tavakoli, D.R. Buttsworth, T.F. Yusaf and M. Faizollahneja, Performance and exhaust emissions of a gasoline engine with ethanol blended gasoline fuels using artificial neural network, Ind. Eng. Chem. Res, 86(5), pp. 630-639, 2009.

[15] I.L. Nwaogazie, Probability and statistics for science and engineering practice, 3rd Edition, De-Adroit Innovation, Nigeria, 2011.

[16] O.A. Francis, A model for blending motor gasoline, case study: Tema Oil Refinery Ltd., M.Sc. Thesis, Kwame Nkrumah University of Science and Technology, 2013.

[17] Chorng H. Twu and John E. Coon, A Generalized Interaction Method for the Prediction of Octane Numbers for Gasoline Blends. Simulation Sciences Inc., 601 South Valencia Avenue, Brea, CA 92621 (USA).

[18] http://www.osha.gov, OSHA Technical Manual. Accessed on 18th October, 2014.

[19] E. Paranghooshi and M. T. Sadeghi, Predicting octane numbers for gasoline blends using artificial neural networks, Hydrocarbon Processing, 2009.

[20] W.F. Schoen and A.V. Mrstik, Calculating gasoline blend octane ratings, Ind. and Engr. Chem., 47(9), 1740-1742, 1955.

[21] W.E. Stewart, Predict Octanes for Gasoline Blend, Petroleum Refiner, 38(12), 135-139, 1959.

[22] M.H. Rusin, H.S. Chung, and J.F. Marshall, A transformation method for calculating the research and motor octane numbers of gasoline blends, Ind. Eng. Chem. Fundam., 20(3), pp. 195-204, 1981.

[23] W.E Morris, "Interaction Approach to Gasoline Blending", NPRA Paper AM-75-30, National Petroleum Refiners Association annual meeting, 1975.

[24] N. Pasadakis, V. Gaganis, Ch. Foteinopoulos: "Octane number prediction for gasoline blends", Fuel Processing Technology, 87, (2006) 505-509.

[25] A. H. Zahed, S. A. Mullah, and M. D. Bashir. Predict Octane Number for Gasoline Blends. Hydroc Proc, 72(5), 1993, 85-87.

[26] G. Prasenjeet, J.H. Karlton, and B.J. Stephen, Development of a detailed gasoline composition-based octane model, Ind. Eng. Chem. Res., pp. 337-345, 2006.

[27] http://www.curvefitting.com, DataFitX version 8.2.79. 